\title{
FROM THE GUEST EDITORS
}

Welcome to the Radiocarbon Proceedings Issue of the 18th International Radiocarbon Conference, held in Wellington, New Zealand, in September 2003. Its appearance is the last step in a process that began 4 years ago, after the 2000 Jerusalem conference.

It was a satisfying feeling on the afternoon of September 5th, 2003, as we knew that the 18th International Radiocarbon Conference had finally taken its place in that long series of conferences that stretches back 50 years. Of course, we had our concerns. The tragedy of September 11, 2001, made the world suddenly look more dangerous than most of us had ever imagined, and the prospect of travelling to distant parts of the globe lost its attraction for many people. The additional menace of the SARS virus outbreak further complicated travel to what, for many of you, was an exceedingly distant shore. Given these factors, who would come to the bottom of the Pacific to attend a conference?

Well, stone the crows, you did come. Whether through heroism, defiance, insouciance or a failure to read the newspapers is not for us to say. We missed some familiar faces, not all for the reasons given above, but there were enough old and new friends to ensure the conference was a success. Because, as with all such events, its success depended finally on the participants and what they made of it. We knew that, ultimately, we were in good hands. There was a touch of sadness when we learned that John Head, well known to many of the "old guard," had passed away just weeks before the conference opened. Also absent was Reidar Nydal, who was prevented from coming by poor health.

What of the conference itself? It is almost with relief to note that talks were not dominated by the next "big thing" in radiocarbon. Rather, the presentations gave us a picture of a field that, although nearly 60 years old, is far from exhausted but rather is expanding into new areas, pushed by developing technology and pulled by new research priorities. AMS, after 30 years, has long since ceased being a novelty, but the continued shrinking of new AMS systems makes one wonder if someone at the next conference will announce the invention of the mass spectrometer.

What is apparent is that the promise of the AMS revolution continues to be fulfilled. Hitherto impossible measurements on hitherto impossible materials seems to be one of the roads to the future. If one were to hazard a guess as to the most promising development beginning to appear, then compound specific dating certainly appears to be the one to watch. The possibility of teasing apart the organic soup that we usually have to deal with, down to its molecular components, just has to lead to surprises in the future.

Another topic that is growing in importance and familiarity is the use of Bayesian methods in the interpretation of radiocarbon ages. The statisticians are persuading us that there is often much more information in our data than we realize, if we look at it in the right way. If they can only break the habit of beginning every paper with "Let $X$ be a random variable with a normal distribution...", the persuasion will be total.

For us, the highlight of the conference was at the dinner when Paul Damon asked why there was no mention of Athol Rafter in all the proceedings. How right Paul was to ask that question! It was a salutary reminder to us of how easy it is to forget the past and the contributions made by those who went before us. Certainly Rodger more than made amends with a five-minute impromptu speech on the Rafter years. 
It remains to thank all those who helped make the 18 th ${ }^{14} \mathrm{C}$ Conference a success. The Rafter Radiocarbon team included Michelle Park, that powerhouse graphics wizard who corrected all the last-minute greeblies in Powerpoint presentations on site. We also acknowledge the daily support of Chris Prior, Jannine Cooper, Lisa Xie, Margaret Norris, Dawn Chambers, Kelly Sutton, Lorraine Gilligan, and Andrei Gaidamaka. Thanks to Janet Simes and her Absolutely Organised team, and the Te Papa staff who made the venue such a fantastic success. The International Advisory Panel diligently reviewed the abstracts that flooded in right on deadline; and we must thank also the reviewers who refereed the papers in this volume. Thanks to the Radiocarbon editorial staff, especially Tim Jull and Mark McClure, who taught us just what goes into creating every issue of the journal. And we very heartily thank our sponsors, especially HVE and NEC, whose major contributions to our budget helped us pull off the conference you all enjoyed so much.

Finally, thanks to all of you who came to Wellington in 2003. Your participation made the conference what it was; we really just tried to put on a good party for you all.

So now, relax before a roaring fire, pour a snifter of brandy, and browse this volume of the 2004 Conference Proceedings, and start thinking about the papers to be written for Oxford in 2006.

Rodger J Sparks

Nancy Beavan Athfield

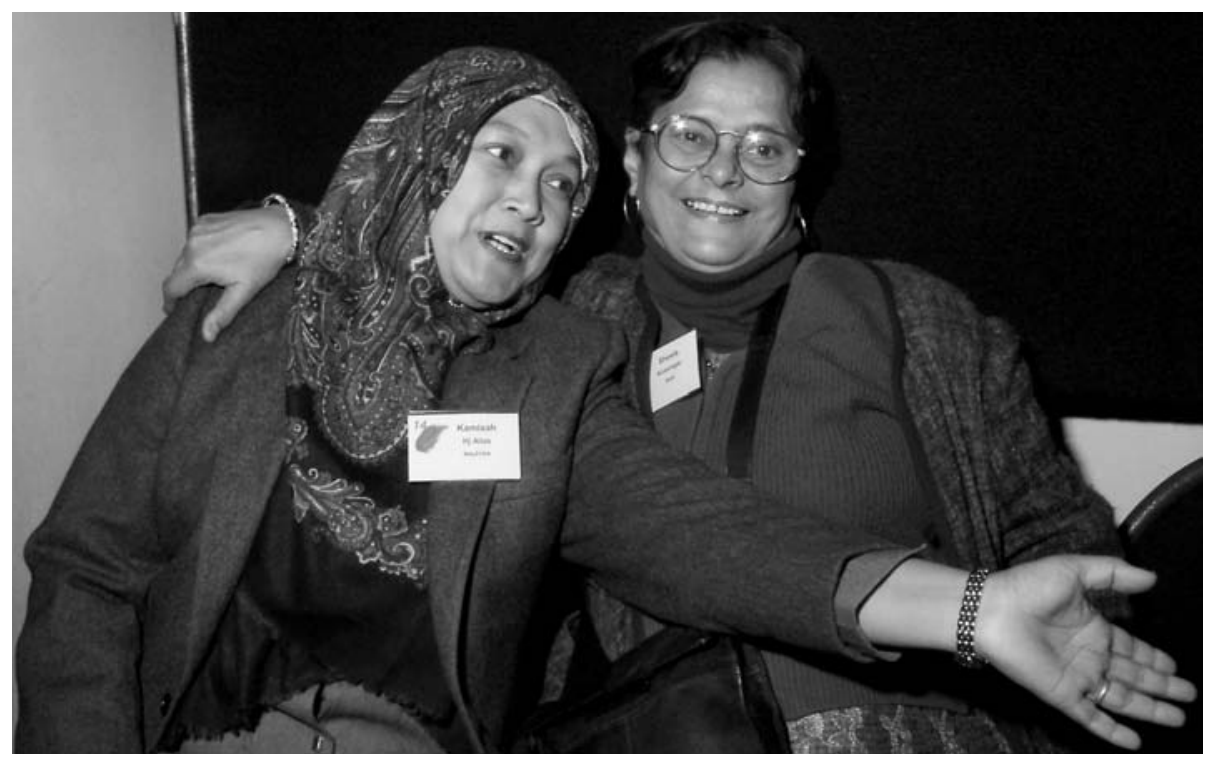

Photos courtesy of Tony Athfield Photographics and Michelle Park. 

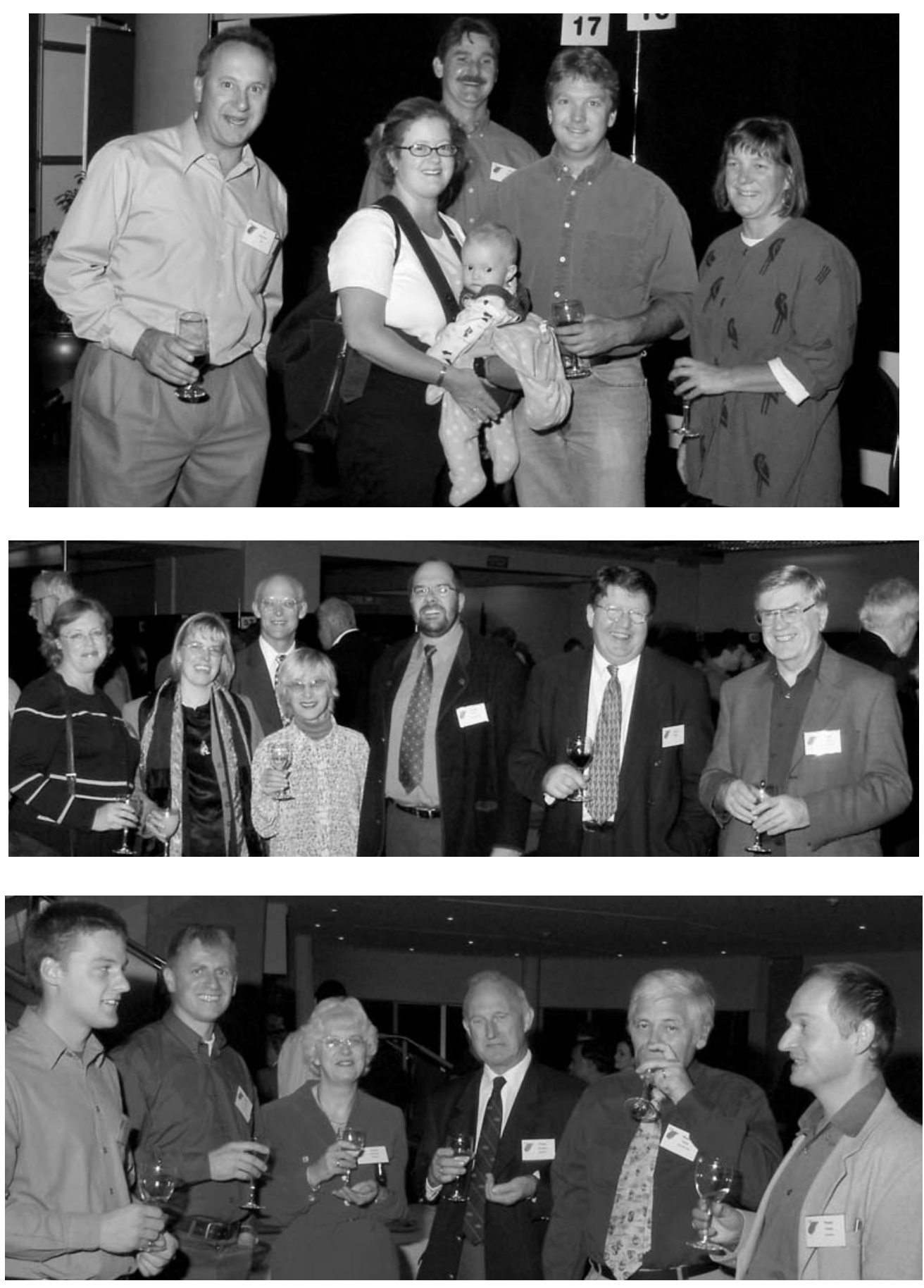

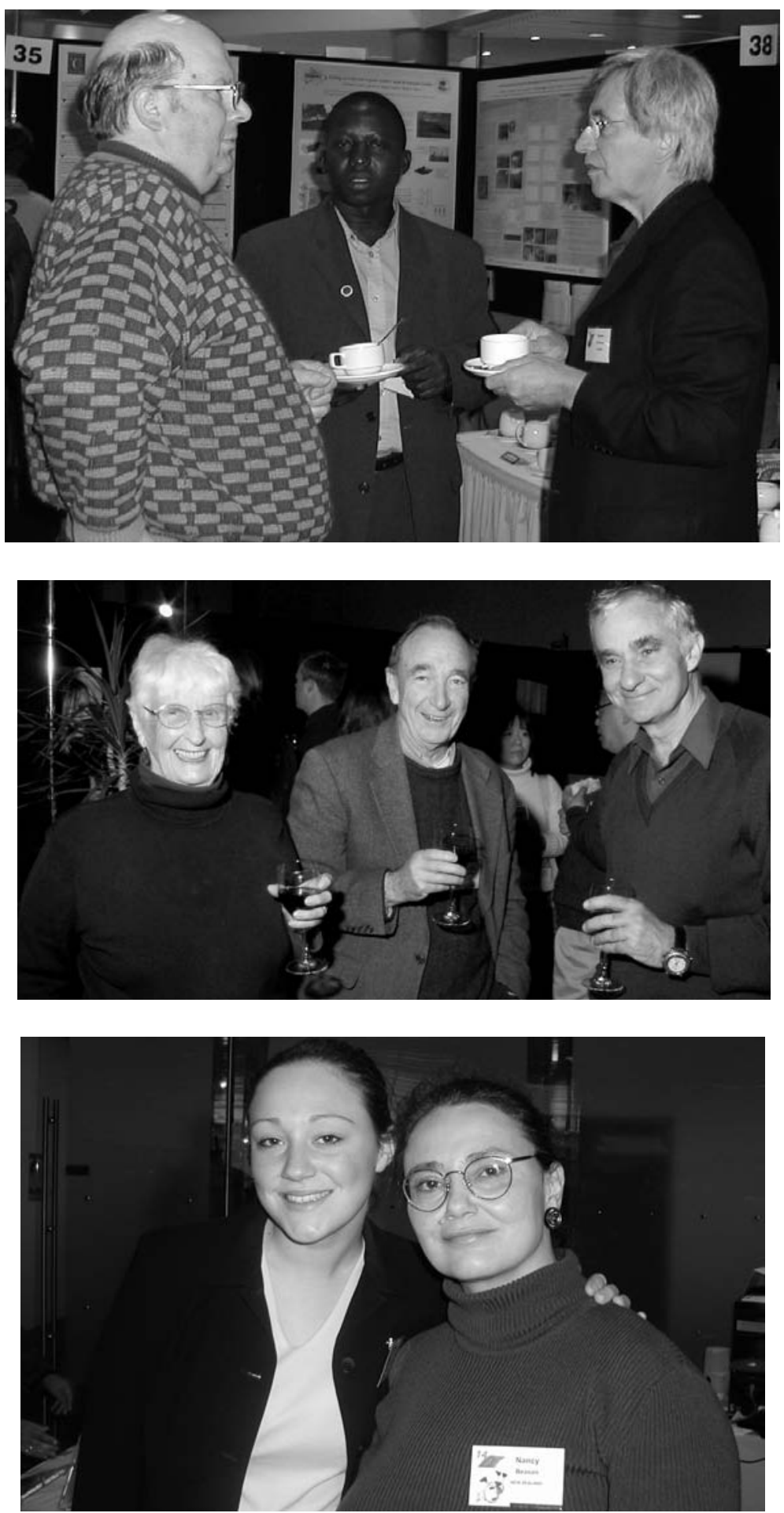

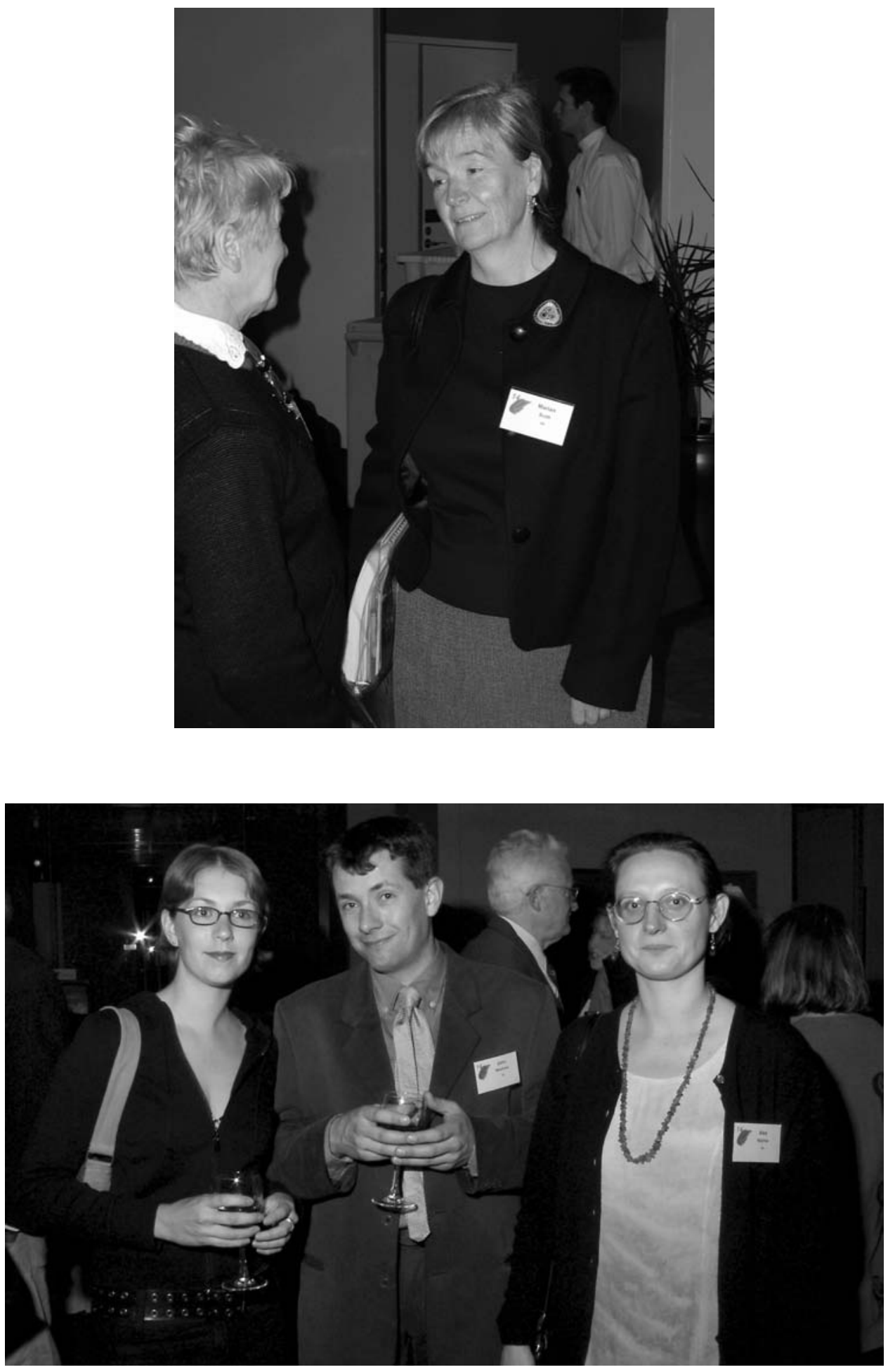


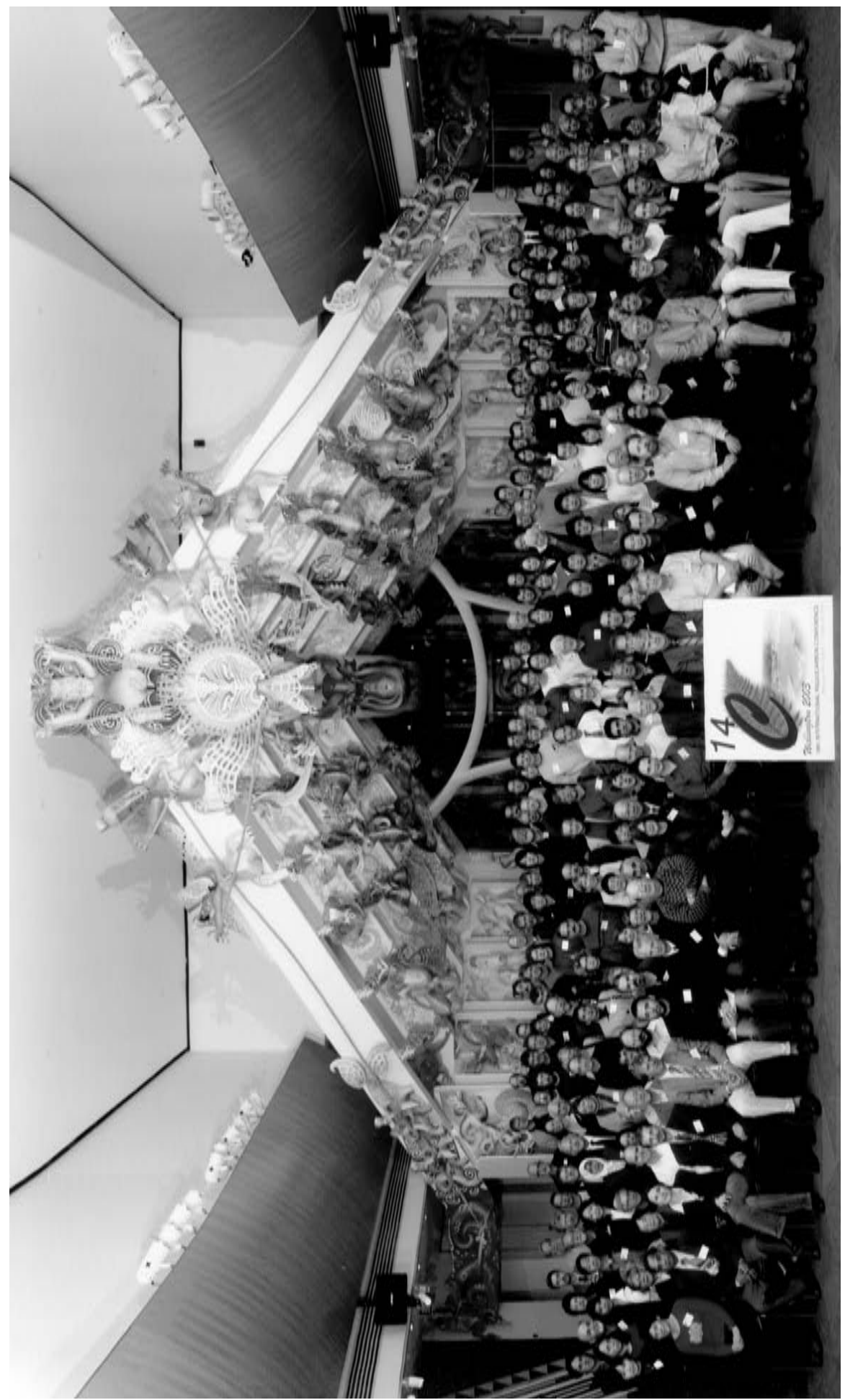

